\title{
DAÑOS MORALES POR INFIDELIDAD MATRIMONIAL. \\ UN ACERCAMIENTO AL DERECHO ESPAÑOL
}

\author{
MORAL DAMAGES CAUSED BY MARITAL INFIDELITY. \\ AN APPROACH TO SPANISH LAW
}

Pamela Mendoza Alonzo ${ }^{1}$

Fecha Recepción: 12/08/2011

Fecha Aprobación: 30/09/2011

\begin{abstract}
Resumen
Este artículo plantea la cuestión de si son susceptibles de ser indemnizados los daños morales causados por infidelidad matrimonial. Se toma como referencia el Derecho español, por el fuerte debate generado por algunas sentencias que han puesto el tema en discusión. Además, revisamos las razones invocadas tradicionalmente por doctrina y jurisprudencia para excluir la aplicación de las normas de Responsabilidad Civil -contractual o extracontractual-en el ámbito del Derecho de familia.
\end{abstract}

Palabras claveĐaños morales - fidelidad - matrimonio.

\begin{abstract}
In this article, we discuss if moral damages caused by marital infidelity could be compensated. We take Spanish law as our point of reference, as, most recently, Spanish courts have put the issue under discussion. Moreover, we investigate the reasons why doctrine and judges are reluctant to apply civil liability -contract or tort Law-in such cases.
\end{abstract}

Key words:Moral damages- fidelity- marriage

1 Abogada. Doctora en Derecho @ Universidad de Salamanca, España. Correo: pamelamendoza@usal.es 


\section{Introducción}

Es innegable que desde antaño ha existido la tendencia a no involucrar algunos aspectos de la responsabilidad civil -contractual o extracontractual-, en el ámbito del Derecho de familia, salvo que existan normas específicas que así lo dispongan. En este orden de cosas, se plantea la duda de si existe efectivamente responsabilidad entre cónyuges por la inobservancia de los deberes conyugales, o son simples deberes éticos, cuya infracción no podría acarrear como consecuencia jurídica la indemnización por los daños y perjuicios que pudieran derivarse de dicho incumplimiento.

Es así como el presente trabajo pretende, tomando básicamente de referencia el Derecho español, describir el estado de la cuestión, deteniéndonos en particular, sobre si cabe aceptar la indemnización del daño moral que es susceptible de producir la infidelidad matrimonial. No obstante, advertimos desde ya que la discusión sigue abierta, por lo que las opiniones que podamos dar al respecto no están exentas de polémica.

Tomamos el caso español por existir un fuerte debate al respecto, a raíz de la creciente presentación en Tribunales de demanda en la cual un cónyuge o ex cónyuge solicita tal indemnización. De este modo, revisaremos junto a dichas sentencias, los principales argumentos que tradicionalmente se han esgrimido para evitar que las normas de la responsabilidad civil se apliquen en las variadas situaciones donde se produce un daño en el marco de las relaciones de familia, y las razones para desestimarlas como tal.

\section{Argumentos en contra de la interposición de acciones civi- les en el ámbito familiar y críticas a los mismos ${ }^{2}$}

\section{La responsabilidad civil es ajena al ámbito familiar}

En general, teniendo en cuenta el modelo patriarcal que han recogido los Códigos Civiles decimonónicos, donde el padre y marido ostentaba la jefatura de la misma, las instituciones de familia se han configurado como un sistema jurídico diferente a otros sectores del Derecho Civil, con principios, finalidades y caracteres especiales. Este régimen de "inmunidad y privilegio matrimonial" ${ }^{3}$ tendría su origen en una costumbre social, en una regla moral que impide que se litigue por hechos cometidos

2 Vid. Sentencia del Tribunal Supremo español de 30 de julio de 1999 (RJ 1999\5726) que las recoge resumidamente.

3 Vargas Aravena, David, Daños civiles en el matrimonio, La Ley, Madrid, 2009, pp. 107 y ss. 
dentro de la familia ${ }^{4}$, pues de no ser así implicaría la desnaturalización de los principios que la constituyen ${ }^{5}$.

Es así como tal regla de moralidad no se encuentra recogida en los Códigos Civiles de manera expresa, ni ha constituido un principio derivado de las resoluciones judiciales ${ }^{6}$. No obstante, se trataría de una regla de moralidad que se explicaría desde la naturaleza propia de las relaciones familiares, de las que se originan vínculos de solidaridad y gratuidad entre los miembros de una familia.

No obstante, esta perspectiva es criticable, pues se ha generado atendiendo circunstancias sociales, económicas, históricas, que no se mantienen necesariamente hoy en día. Efectivamente, considerando que la idea de familia evoluciona, sustituyéndose el modelo patriarcal por otro -basado en el principio de igualdad de los cónyuges y en el de titularidad y ejercicio conjunto de la patria potestad- se hace inevitable la intervención de los Tribunales ${ }^{7}$. De este modo, se asegura la efectividad de dicho principio, así como el respeto de los derechos fundamentales e intereses legítimos de los miembros de la familia.

Esta evolución en la concepción de familia, que ha llevado, a juicio de algunos, a una tasa elevada de separaciones, divorcios y familias recompuestas, viene a reducir los factores morales que tradicionalmente han inhibido la exigencia de establecer consecuencias jurídicas por actos dañosos entre familiares, pues no es menos cierto, que la familia ya no se aprecia forzosamente como una "unidad de cooperación a largo plazo" ${ }^{\prime \prime}$.

Justamente, se puede entender que las normas jurídicas vayan desplazando sistemáticamente a las normas sociales. De este modo, aunque sigue siendo innegable una cierta prevalencia de estas últimas, la propia dinámica social genera cada vez

4 Patti, Salvatore, Famiglia e responsabilità civile, Giuffrè, Milán, 1984, pp. 67, 104 y 121.

5 Fleitas Ortiz de Rozas, Abel, Responsabilidad por daños y perjuicios entre cónyuges [on line], [última consulta: 15 de marzo 2010]. Disponible en la World Wide Web: http://www.rubinzal.com.ar/revistas/danos/danoenlarelacion_defamilia(danos)-e.htm\#2,

6 Rodríguez Guitián, Alma, Responsabilidad civil en el derecho de familia: Especial referencia al ámbito de las relaciones paterno-filiales, Aranzadi, Pamplona, 2009, pp. 35-37.

7 De Verda y Beamonte, José, Responsabilidad civil y divorcio en el derecho español: resarcimiento del daño moral derivado del incumplimiento de deberes conyugales/en/ Diario La Ley, n 6676, 21 de marzo de 2007, [última consulta: 31 de julio de 2011]. Disponible en World Wide Web: http://www.laley.es.

8 Ferrer Riba, Josep, Relaciones familiares y límites del derecho de daños /en/ Cabanillas Sánchez, Antonio, et al. (coord.), Estudios jurídicos en homenaje al profesor Luis Díez-Picazo, T. II, Civitas, Madrid, 2003, p. 1840. 
más situaciones que obligan a pronunciarse sobre su viabilidad jurídica ${ }^{9}$, no siendo más el Derecho de Familia un campo de inmunidad en este aspecto $^{10}$.

\section{Deberes conyugales son deberes ético-morales, no jurídicos}

Estrechamente ligada con la anterior, nos encontramos con la idea que los deberes conyugales no constituirían obligaciones jurídicas en sentido estricto, sino que su naturaleza sería la de ser simples deberes ético-morales cuyo cumplimiento se encuentra sometido a la conciencia de los cónyuges, siendo incoercibles en su esencia. Efectivamente, no tendría sentido la aplicación de medios dirigidos a la compulsión, aunque sea indirecta, de los mismos, debiendo mantenerse, por las mismas características de la vida familiar, en un contexto de libertad y no gracias a la amenaza de remedios resarcitorios ${ }^{11}$.

En cuanto al origen de esta visión respecto a los deberes conyugales, advierte Sancho Rebullida que fue la escuela histórica la que puso en duda la pertenencia de estos preceptos en el ámbito del Derecho. Precisamente, se entendía que dichas virtudes se imponían por la costumbre, y no por la ley, y que, en definitiva, debiera dejarse la ordenación de las relaciones familiares, en primera línea, a los miembros de la familia y a su sentido moral. Opuestamente -señala este autor- "la escuela de la exégesis insistía en un planteamiento positivista..."12.

Cuestionando su naturaleza como deberes jurídicos, ya se había pronunciado el Tribunal Supremo español, en sentencia de 4 de diciembre de 1959 (RJ 1959/4483), al considerar que: "Los derechos y deberes derivados de la relación matrimonial son especialmente recíprocos, porque incumben y corresponden a ambos cónyuges, a quien se estima una situación de paridad, teniendo un carácter marcadamente ético, porque se confía al sentimiento y a la conciencia íntima el cumplimiento de tales deberes, y de aquí las consecuencias que las normas reguladoras de esta relación, aun siendo jurídicas por haber sido acogidas en el Código Civil acusan su origen en lo tenue de la sanción que frecuentemente era solo patrimonial, siempre indirecta y un

9 Ibidem.

10 Roca I Trías, Encarna, La responsabilidad civil en el derecho de familia. Venturas y desventuras de cónyuges, padres e hijos en el mundo de la responsabilidad civil /en/ Moreno Martínez, Juan (Coord.), Perfiles de la responsabilidad civil en el nuevo milenio, Dykinson, Madrid, 2000, pp. 534-537

11 Rodríguez Guitián, Alma, obr. cit., pp. 100 y ss.

12 Lacruz Berdejo, José y Sancho Rebullida, Francisco, Elementos de Derecho Civil IV. Derecho de Familia, Bosch, Barcelona, 1982, p. 179. 
poco eficaz... cuya observancia depende más de la conciencia que el frío precepto legal"13.

No obstante, definir la naturaleza jurídica de los deberes conyugales no es tarea fácil, todavía si consideramos que, sobre la naturaleza misma del matrimonio no existe una respuesta del todo satisfactoria ${ }^{14}$. Sin embargo, sea el matrimonio un contrato o un negocio jurídico diverso, no es menos cierto que, si pretendemos mantener el matrimonio con su naturaleza jurídica, hoy en día el carácter jurídico de los deberes conyugales debería estar fuera de discusión ${ }^{15}$, pues no se puede desconocer que, además, estos integran el núcleo mismo de la causa matrimonial ${ }^{16}$.

Así, el carácter jurídico de los deberes conyugales no les priva de ser considerados también como deberes ético-morales, o viceversa, su carácter ético o moral no les priva de su juridicidad. En efecto, no es menos cierto que existen innumerables normas éticas o morales que han sido incorporadas al ordenamiento jurídico, normas que por su parte tienen una sanción en este y coercibilidad directa, como sería el "no robar", "no matar", etc. ${ }^{17}$.

Cabe recordar que la misma ley 15/2005 de 8 de julio -por la que se modifican el Código Civil y la Ley de Enjuiciamiento Civil en materia de separación y divorciointroduce nuevos deberes en el artículo 68 del Código Civil. Si bien hay opiniones

13 Al respecto vid. Vargas Aravena, David, obr. cit. p. 131, nota 217.

En el mismo sentido, se han manifestado los tribunales chilenos, v. gr. la Corte de Apelaciones de Santiago en sentencia de 10 de noviembre de 2009 (ROL 7738-07), al rechazar la petición de daños morales del marido por infidelidad de la mujer, por estimar que, naturalmente, "las relaciones de familia tienen un fuerte componente ético que sobrepasa, con mucho, el ámbito estrictamente jurídico..." (considerando 15). Disponible en: http://poderjudicial.cl.

Refiriéndose a la jurisprudencia argentina, Medina describe que en un principio, ajustándose al texto legal, se negó la procedencia de la indemnización de daños morales por infidelidad destacando que "es histórico el fallo de Borda siendo juez civil de primera instancia de la Capital Federal en 1957, donde además sostuvo que admitir un reclamo de ese tipo era contrario a la moral y buenas costumbres...". Medina, Graciela, Daños derivados del divorcio [on line], [última consulta: 31 de julio de 2011]. Disponible en World Wide Web: http://www.gracielamedina.com/assets/Uploads/articulo/pdf/0911-06A-1.pdf

14 Esta discusión no es baladí, pues si estimamos que el matrimonio no es un contrato, de entender que cabría el resarcimiento de los daños producto del quebrantamiento de los deberes familiares, solo podría invocarse en sede extracontractual, discusión sobre la que se volverá más adelante.

15 Llamas Pombo, Eugenio, Divorcio y responsabilidad civil /en/ Práctica de derecho de Daños: Revista de responsabilidad civil y seguros, $\mathrm{n}^{\circ} 49$, mayo 2007, pp.3-4.

16 De Verda y Beamonte, José, obr. cit., p. 5.

17 Sancho Villarreal, Luis, El deber de fidelidad conyugal como obligación jurídica y consecuencias de su infracción. Comentario a la STS de 30 de julio de 1999 /en/ Revista de derecho de familia, abril 2001, p. 82 . 
que esta introducción carece de eficacia jurídica ${ }^{18}$, no es menos cierto, que al no aprovecharse la ocasión de eliminarlos, más que convertirlos en meros deberes morales, lo que se ha conseguido es resaltar su carácter jurídico. Efectivamente, el solo hecho de su consagración misma en el Código Civil les estaría dando dicho carácter ${ }^{19}$.

Asimismo, no hay que olvidar lo que sostenía SANCHO ReBullida ya antes de esta reforma, a propósito del deber de fidelidad y despenalización del adulterio, pues aunque se restrinjan ciertos presupuestos del deber de fidelidad; hayan cambiado las formas de tutela de tal deber, y por tanto las consecuencias de su infracción; persiste el deber mismo, "sigue constituyendo el adulterio una grave infracción de la fe conyugal... varían los efectos de la infracción, pero no la regla que impone el deber infringido" ${ }^{20}$. El deber de fidelidad, como el resto de los deberes conyugales, constituye una obligación jurídica, que aunque varíe su configuración legal, mientras persista como tal tiene plena eficacia ${ }^{21}$.

En conclusión, los deberes conyugales consagrados en el Código Civil son obligaciones jurídicas que el cónyuge debe respetar, debido a que existen normas legales que contienen un mandato de tipo positivo al respecto, cuyo incumplimiento puede traer aparejadas consecuencias jurídicas más allá del principio de especialidad-que veremos a continuación- y que los tribunales están Ilamados a determinar.

En consideración a lo afirmado, solo entonces quedaría en cuestión la extensión del deber de fidelidad, y en este orden de cosas, algunos autores sostienen que hoy en día el deber de fidelidad no se circunscribiría netamente su extensión a su dimensión sexual sino que a toda la amplitud de su concepción moral. En este sentido sostiene Sancho Villarreal que el deber de fidelidad consagrado en el art. 68 Cc. también se quebrantaría en supuestos tales como la interrupción del uso de anticonceptivos

18 Así lo estima Vázquez Iruzubieta, Carlos, Comentario al artículo 68 del Código Civil /en/ Matrimonio, separación y divorcio. Comentarios a los artículos 42 a 107 del Código Civil, Vlex, 2009 [on line], [última consulta: 31 de julio de 2011]. Disponible en World Wide Web: http://vlex.com/source/matrimonionulidad-separacion-divorcio-comentario-codigo-civil-608\#ixzz0kuxhlEpL

19 Así lo estima Vázquez Iruzubieta, Carlos, Comentario al artículo 68 del Código Civil /en/ Matrimonio, separación y divorcio. Comentarios a los artículos 42 a 107 del Código Civil, Vlex, 2009 [on line], [última consulta: 31 de julio de 2011]. Disponible en World Wide Web: http://vlex.com/source/matrimonionulidad-separacion-divorcio-comentario-codigo-civil-608\#ixzz0kuxhIEpL

20 Novales Alquézar, María, Hacia una teoría general de la responsabilidad civil en el derecho de familia. El ámbito de las relaciones personales entre cónyuges /en/ Revista jurídica del notariado, nº 60, octubre-noviembre 2006, p. 201.

En este sentido, De Verda y Beamonte, José, cit. considera que "la supresión, como causa de separación, del incumplimiento de los deberes conyugales, operada por la Ley 15/2005, de 8 de julio, no es argumento para negar la juridicidad de los deberes conyugales, pues esta nueva orientación legal se explica en un planteamiento general, de eliminación de todas causas de separación o divorcio, distintas de la mera voluntad de los cónyuges de seguir conviviendo".

21 Lacruz Berdejo, José y Sancho Rebullida, Francisco, obr. cit., p. 184. 
sin aviso a la otra parte, o el asegurar su uso de estas sin haberlo hecho en realidad, esterilización o aborto contra la voluntad del otro cónyuge o el uso de cualquier medio de reproducción asistida por parte de la mujer sin consentimiento del marido ${ }^{22}$. Por otra parte Marín GaRCía de LeONARDo destaca que en la actualidad el deber de fidelidad se trata de un "no traicionar en un sentido amplio no solo sexual, ni solo afectivo" entendiendo que se podría incluir dentro de esta "el no traicionar la confianza recíproca, la obligación recíproca de lealtad, el no descuidar la dedicación física y espiritual del otro cónyuge" 23 .

No obstante, pareciera ser que el art. 68 Cc. alude concretamente al aspecto sexual de la pareja. Efectivamente, seguimos la interpretación tradicional que circunscribe el deber de fidelidad en dos aspectos: uno positivo, relativo a la consumación del matrimonio -recíproca disponibilidad a mantener relaciones sexuales entre sí- y otro aspecto negativo, que implica exclusividad de relaciones sexuales entre cónyuges, y por ende prohibición de tenerlas con terceros ${ }^{24}$. Asunto distinto es determinar cuándo dicho comportamiento es susceptible de ser indemnizado y por cuál vía.

\section{Principio de especialidad en el Derecho de Familia}

Por otra parte, tradicionalmente se ha sostenido que los cónyuges tendrían un régimen de derechos, deberes, responsabilidades y sanciones totalmente específico, que se vería desnaturalizado si se les introducen otras de distinto tipo ${ }^{25}$, pues se le estaría dando una perspectiva individualista, incompatible con el interés superior de la familia.

En este orden de cosas, básicamente existirían dos posibles tipos de remedios entre cónyuges de acuerdo a la legislación española:

(i) Los que prevén una forma de resarcimiento definida: como sería la responsabilidad existente en las relaciones patrimoniales entre los cónyuges, pero limitada al régimen de bienes (artículos 1390 y 1391 Código Civil), y el derecho a pensión compensatoria del cónyuge en caso de divorcio (Artículo 97 Código Civil), como asimismo, lo sería la indemnización que contempla el artículo 98 a favor del cónyuge de buena fe que sufre daños tras la nulidad matrimonial.

22 Sancho Villarreal, Luis, obr. cit., p.87.

23 Marín García de Leonardo, Teresa, Remedios indemnizatorios en el ámbito de las relaciones conyugales /en/ De Verda y Beamonte, José (coord.) Daños en el derecho de familia, Aranzadi, 2006, p. 151.

24 Lacruz Berdejo, José Luis y Sancho Rebullida, Francisco de Asís, obr. cit. p. 182.

25 Fleitas Ortiz de Rozas, Abel, obr. cit. 
(ii) Los que prevén otros remedios distintos al resarcimiento: como lo sería ser causal de separación y divorcio (antiguos artículo 82 y 86 del Código Civil), cese de derechos alimenticios (artículo $152 \mathrm{n}^{\circ} 4$ Código Civil), causal de desheredamiento (artículo 855 n $^{0} 1$ Código Civil) así como ser causa de revocación de donaciones entre contrayentes (artículo 1343 Código Civil).

Revisaremos los dos más relevantes para nuestro estudio.

\subsection{Incumplimiento de los deberes conyugales como causal de separa- ción y divorcio}

Tradicionalmente en el Derecho español -al menos hasta la dictación de la ley 15/2005-, se entendió que el ser causal de separación e indirectamente de divorcio, era "la consecuencia jurídica" en caso de incumplimiento de los deberes conyuga$l^{2} s^{26}$. Sin embargo, hoy en día no puede conceptualizarse la separación y divorcio como una sanción propiamente tal, sino más bien como una vía de resolución de las crisis matrimoniales, debido a la peculiar e inédita reforma que eliminó la separación y divorcio por causa ${ }^{27}$.

Situación diversa podemos observar, por ejemplo, en la legislación chilena. Efectivamente, con la existencia de la modalidad de la separación y divorcio-sanción de los artículos 26 y 54 Ley 19947, dicho argumento seguiría teniendo absoluta vigencia, como en la mayoría de las legislaciones que aún la contemplan ${ }^{28}$.

26 En este sentido Roca I Trías quien al analizar los daños y causas de la separación estimaba que en esos casos, no habría indemnizaciones, "pues el daño ha quedado tipificado con una consecuencia clara y diáfana: la posibilidad por parte del cónyuge inocente, del perjudicado en definitiva, de pedir la separación". Roca I Trías, Encarna, obr. cit., p. 547; Ferrer Riba, Josep, obr. cit., pp. 1854-1855.

Esta postura fue recalcada en su momento por el Tribunal Supremo en la citada sentencia de 30 de julio de 1999 (RJ 1999\5726), al considerarla como "la única consecuencia jurídica que contempla nuestra legislación substantiva...".

27 Vid. Domínguez Muelmo, Andrés, La supresión de las causas de separación y divorcio en la ley 15/2005 y sus repercusiones en el Derecho Civil /en/ Revista jurídica de Castilla y León, no 13, agosto 2007, pp. 53-111.

28 Sin perjuicio que al menos la jurisprudencia italiana y francesa manifiestan la tendencia contraria, así lo destaca De Verda y Beamonte, José, obr. cit.

No obstante, en Chile, la sentencia de la Corte de Apelaciones de Santiago de 10 de noviembre 2009 (ROL 7738-07), sostiene fehacientemente que el principio de especialidad prima en aquellos casos en que se ha producido daño entre cónyuges, pues estima que "teniendo presente el cúmulo de disposiciones que sancionaban y sancionan el adulterio, es posible concluir que el adulterio, desde siempre, ha sido calificado por el legislador como infracción grave al deber de fidelidad de los cónyuges y no como delito o cuasidelito civil. En efecto, los diferentes ordenamientos jurídicos han tratado de mantener los conflictos matrimoniales dentro de cierto grado de discreción, por lo cual, los legisladores, anticipándose al conflicto, han precisado las consecuencias de la infracción, como en el caso de autos, al deber de fidelidad. Es decir, el derecho de familia por su especialidad, contempla sus propias sanciones, no siendo aplicable en consecuencia, las normas generales sobre responsabilidad civil y por ende no corresponde -en un caso como el de autos- solicitar ni mucho menos conceder la reparación del daño moral (considerando decimonoveno). 
No obstante, aun si en el Derecho español estuvieran vigentes los artículos 82 y 86 del Código Civil, creemos que este argumento ofrece una protección limitada al cónyuge que sufre una violación al derecho de fidelidad y a la generalidad de los deberes conyugales. Precisamente, debe tenerse en consideración que en algunos supuestos de incumplimiento se encontrarían en juego la lesión de derechos fundamentales, tales como el honor, integridad física y psíquica, etc. que frenaría con esta forma de interpretación la protección constitucional establecida ${ }^{29}$.

Por otra parte una postura que excluya tajantemente las normas de responsabilidad civil -ya sea contractual o extracontractual- del ámbito familiar, olvida que el Derecho es esencialmente unitario, por lo que las normas se encuentran necesariamente interrelacionadas, y por ende, si existe un daño en la familia, se deben aplicar las normas y vías que se estimen convenientes para resarcirlo ${ }^{30}$.

\subsection{Recurso a la figura de la pensión compensatoria en caso de separa- ción y divorcio}

Por último, podría argumentarse para desestimar una reclamación por daños morales (aunque extensibles a los patrimoniales) producto de la infidelidad conyugal, el hecho de existir la figura de la pensión compensatoria en caso de divorcio como forma de resarcimiento única y específica contemplada por el legislador español en el artículo 97 del Código Civil.

No obstante que la naturaleza jurídica de dicha figura -indemnizatoria, alimenticia, compensatoria- no ha resultado clara ${ }^{31}$, podría afirmarse que existe un cierto consenso respecto a su finalidad esencialmente compensatoria-reparadora. En definitiva, su nota característica es la existencia de un "desequilibrio económico" -independiente de la culpa o participación en la ruptura de los cónyuges-, en el que

29 En este sentido, Rodríguez Guitián, Alma, obr. cit., p. 120.

Criticando el argumento dado por el Tribunal Supremo Ragel Sánchez pone hincapié en que por ejemplo no hay que ir demasiado lejos para demostrar que los malos tratos con resultado de lesiones caben en la esfera de la sanción penal, como asimismo delitos tipificados derivados de incumplimiento de deberes conyugales. Es así como destaca que en todos estos casos que acarrean una responsabilidad penal podrá también existir una responsabilidad civil como consecuencia de un comportamiento delictual que a la vez es incumplimiento de deberes conyugales "en todos estos supuestos, el incumplimiento conyugal puede acarrear consecuencias económicas desfavorables para el cónyuge infractor, con independencia de que se ejercite o no la acción de separación matrimonial". Ragel Sánchez, Luis, Denegación de indemnización del daño moral causado por infidelidad matrimonial. Comentario a STS de 30 de julio de 1999 /en/ Cuadernos Civitas de jurisprudencia civil, nº 52, enero-marzo 2000, p. 159.

30 Rodríguez Guitián, Alma, obr. cit., p. 101.

31 Vargas Aravena, David, obr. cit., p. 164. 
se pretende subsanar el perjuicio material que resulta para uno de los cónyuges del divorcio o de la separación conyugal ${ }^{32}$.

Efectivamente, solo si hay desequilibrio habrá pensión ${ }^{33}$, y ya sostenía RocA TRíAs que el presupuesto esencial para que brote este derecho "será la desigualdad que resulta de la confrontación entre las condiciones económicas de cada consorte antes y después de la ruptura; la desigualdad existía en realidad durante el matrimonio, pero la vigencia de los deberes de socorro y ayuda mutuos lo eliminaban..." ${ }^{\prime 34}$.

En este sentido, se ha manifestado el Tribunal Supremo español, entre otras, en la sentencia de 10 de febrero de 2005 (RJ 2005\1133), al señalar en su considerando segundo que "del precepto (artículo 97 Código Civil), se deduce que la pensión compensatoria tiene una finalidad reequilibradora. Responde a un presupuesto básico: el efectivo desequilibrio económico, producido con motivo de la separación o el divorcio, en uno de los cónyuges que implica un empeoramiento económico en relación con la situación existente constante matrimonio..." ${ }^{\prime 35}$.

En conclusión, y atendiendo su naturaleza esencialmente compensatoria, razón tenía en este sentido la sentencia del Tribunal Supremo español de 30 de julio de 1999 (RJ 1999\5726), al señalar que del incumplimiento de los deberes conyugales, no deriva ningún efecto económico asociado a esta figura, pues "de ningún modo es posible comprenderles dentro del caso de pensión compensatoria que se regula en el artículo 97".

Sin embargo, esta afirmación no se traduce en negar que aquel cónyuge que haya padecido algún daño, cuya causa sea el incumplimiento de los deberes conyugales durante la vigencia de su matrimonio, no tenga derecho a indemnización, acción que no es incompatible con la petición de la pensión compensatoria ${ }^{36}$.

Luego, en este sentido no es posible subsumir ambas figuras, por existir notables diferencias: en primer lugar, por tener la pensión compensatoria, finalidades eviden-

32 Rodríguez Guitián, Alma, obr. cit., p. 106.

33 Roca I Trías, Encarna, obr. cit., p. 548.

34 Ibidem.

35 En Chile, se ha pronunciado en el mismo sentido, entre otras, la Corte de Apelaciones de Punta Arenas, en sentencia de 9 de febrero de 2008 (ROL 307-2008), al señalar que "la compensación económica tiene un carácter reparatorio, no indemnizatorio, porque no se trata de una responsabilidad civil y tanto así que no exige culpa del demandado. Se trata de una forma de resarcimiento de un cierto daño, es decir, de una cierta pérdida producida al cónyuge beneficiario por el hecho de haber dedicado el esfuerzo de vida al cuidado de los hijos o a las tareas del hogar común y que ha impedido por lo mismo, una vida de trabajo con resultado económico y que permita así enfrentar la vida futura una vez producida la extinción del matrimonio... (considerando cuarto)".

36 Vargas Aravena, David, obr. cit., p. 170. 
temente diferentes a la Responsabilidad Civil -ya sea contractual o extracontractual-; pues a grandes rasgos, una pretende reparar un desequilibrio o menoscabo económico entre los cónyuges - debiendo verificarse requisitos objetivos-, mientras que la otra intentaría resarcir el daño producido por el incumplimiento de los deberes conyugales. Por otro lado, los presupuestos de ambas son distintos, pues la pensión compensatoria se liga a una situación objetiva de desequilibrio o menoscabo económico; y si miramos la responsabilidad del cónyuge, esta solo surgiría cuando la conducta dolosa o culposa del cónyuge que incumple sus deberes causa al otro un daño. Y finalmente, porque es posible que el cónyuge que deba percibir la pensión compensatoria y el que tenga derecho a ser resarcido no sea el mismo ${ }^{37}$.

Es así como esta última característica sería una de las motivaciones por la que, la jurisprudencia española rechazaría que del incumplimiento del deber de fidelidad pueda nacer una pretensión indemnizatoria cuando el marido es quien ha sido engañado. En efecto, esta doctrina, advierte Carrasco Perera "tiene como justificación el propósito de no socavar por vía de indemnización (a favor del marido) la pensión compensatoria que pueda corresponder a la mujer separada. Y como excusa, un pretendido derecho personalísimo a desarrollarse libremente como adúltero..." ${ }^{38}$.

En definitiva, si estimamos que la única salvaguarda que existe en los casos de daños entre cónyuges, son los remedios que han sido mencionados, la protección ofrecida estaría muy limitada, pues no todo daño efectivamente causado entre estos es objeto de reparación en la normativa que a grandes rasgos se ha citado. Además, no hay normas en Derecho español que limiten expresamente el ejercicio de otras posibles acciones para obtener la indemnización por los daños sufridos -especialmente morales- si se cumplen los presupuestos de responsabilidad requeridos.

\section{Vías para reclamar el incumplimiento del deber de fidelidad}

Por las razones expuestas, podemos afirmar que hoy en día la concepción tradicional sobre esta materia es fuertemente criticable, por lo que actualmente es sostenida solo por una parte minoritaria de la doctrina ${ }^{39}$. No obstante, subsiste el dilema de determinar la vía para poder reclamar la responsabilidad civil, si debe hacerse en sede contractual -art. 1101 Cc.- o extracontractual -art. 1902 Cc.-.

37 De Verda y Beamonte, José, obr. cit., p. 7.

38 Carrasco Perera, Miguel, El precio de la infidelidad /en/ Actualidad Jurídica Aranzadi, nº 666, abril 2005, p. 3.

39 Vid. por todos Roca I Trías, Encarna, obr. cit., p. 547; Ferrer Riba, Josep, obr. cit., pp. 1854-1855, aunque cabe destacar que dichas opiniones se expresaron con anterioridad a la vigencia de la Ley 15/2005. 
Sobre este punto no existe un acuerdo unánime ${ }^{40}$ pues, entre otros factores, está supeditado a si estimamos el matrimonio como un contrato o no. Es así como, en este orden de cosas, podemos observar dos tendencias al respecto ${ }^{41}$.

(i) Los que sostienen que en dichos casos corresponde la aplicación del art. 1902 del Cc. concurriendo los requisitos exigidos para ello. De este modo, según un sector de la doctrina, la infidelidad sí puede originar un daño moral susceptible de ser indemnizado en sede extracontractual, pero dependerá del caso concreto, y más bien considerando los factores de gravedad, reiteración y consecuencias que deriven de esta, v. gr. si se vulneran derechos fundamentales o bienes del otro cónyuge dignos de tutela jurídica, siendo labor del juez el determinarlos en el caso concreto ${ }^{42}$.

En este orden de cosas, se descartaría la posibilidad de resarcimiento de los daños por parte del cónyuge infiel, si el matrimonio no se ha separado o divorciado, pues se aplica la máxima "love it or leave it", es decir, no será tan importante si a pesar de todo, se sigue viviendo con el cónyuge infiel, por lo que no valdrá la pena mover el aparataje judicial dando curso a demandas contradictorias entre quienes aún siguen durmiendo juntos ${ }^{43}$.

Asimismo, se descarta dicha posibilidad de no poder probarse adecuadamente la existencia de los mencionados daños por parte de quien lo invoca, según las reglas generales ${ }^{44}$.

40 Cuestión de enorme trascendencia práctica al menos en el derecho español, atendida la significativa diferencia entre plazos de prescripción para una u otra: 15 años para la contractual y solo 1 tratándose de responsabilidad civil extracontractual desde que el agraviado sufrió el daño (artículos 1968 y 1964 del Código Civil) situación que no es el caso del Derecho chileno, donde la acción de responsabilidad extracontractual prescribe en 4 años contados desde la perpetración del acto (artículo 2332 Código Civil), mientras la de responsabilidad contractual está sometida al estatuto general de prescripción de las acciones personales ordinarias de 5 años contados desde que la obligación se hizo exigible (artículo 2515).

41 Vid. detallada descripción de las posturas doctrinales que realiza Colás Escandón, Ana, Nuevos daños indemnizables: las relaciones de familia /en/ Herrador Guardia, Mariano (coord.) Derecho de Daños, Sepin, Madrid, 2011, pp. 332-336.

42 En este sentido Rodríguez Guitián, obr. cit., pp. 72-77; Marín García de Leonardo, Teresa, obr. cit., p. 160; López de la Cruz, Laura, El resarcimiento del daño moral ocasionado por el incumplimiento de los deberes conyugales /en/ Indret, 4/2010, p. 16, [on line], [última consulta: 31 de julio de 2011]. Disponible en World Wide Web: http://www.indret.com/es/; Colás Escandón, Ana, obr. cit., pp. 348-352.

43 Como increpa Carrasco Perera- sería mejor en un caso así que "lleguen a un acuerdo o presenten una demanda de separación y divorcio, es lo más que se puede decir desde fuera". Carrasco Perera, Ángel, Derecho de familia. Casos, reglas, argumentos, Dilex, Madrid, 2006, p. 527.

44 Es decir, existencia de una acción u omisión que sea antijurídica, que cause un daño, que sea imputable a la conducta dolosa o culposa del cónyuge y finalmente, la existencia de un nexo causal entre la acción u omisión y el daño producido. Vid. al respecto Colás Escandón, Ana, obr. cit., pp. 350-352. 
(ii) Por otro lado, otra corriente doctrinal estima que el daño provocado por el incumplimiento del deber de fidelidad, se enmarca dentro del ámbito contractual u obligacional -art. 1101 Cc. $-{ }^{45}$. Así, quienes sustentan esta postura, estiman que el matrimonio es un contrato $^{46}$-intuitu personae y sui generis por excelencia- pero en un sentido amplio, es decir, "como acuerdo de voluntades o negocio jurídico bilateral; pero no en su acepción rigurosa, que se reduce a los acuerdos de voluntades en materia patrimonial..." ${ }^{47}$.

En este orden de cosas, tal carácter situaría el incumplimiento de los deberes conyugales dentro del amplio espectro de la responsabilidad civil contractual u obligacional, que comprende otros supuestos distintos del contrato en sentido estricto,

45 En este sentido entre otros Sancho Villarreal, Luis, obr. cit., pp.126; Ragel Sánchez, Luis, obr. cit., p. 163; Llamas Pombo, Eugenio, cit; Nieto Alonso, Antonia, Daños morales derivados del incumplimiento o defectuoso cumplimiento de una obligación contractual (a propósito de alguna jurisprudencia reciente) /en/ Anuario de Derecho Civil, Vol. 59, n 3, 2006, pp. 1115- 1198; Pérez Mayor, Adrián, Crisis matrimoniales e indemnización por daño moral /en/ Revista jurídica de Catalunya, no 1, año CIII, 2004, pp. 167-168, argumentando este último que esto es no solo por tratarse el matrimonio de un contrato intuito personae por naturaleza, "sino por la debida exigencia, para que exista un daño moral reparable y la concurrencia del dolo especialmente en supuestos de nulidad... y ello de acuerdo a las exigencias de la buena fe (artículo 1258 Código Civil).

46 En este orden de cosas, cabe mencionar -según Ramos Pazos- que la tesis que considera el matrimonio como un contrato, fue la dominante en los siglos XVII al XIX y que los canonistas ya lo habían sostenido aduciendo que el vínculo matrimonial derivaba del acuerdo de las voluntades entre los esposos, recalcando que esta postura es la que ha prevalecido entre los juristas franceses e italianos. Es así como destaca este autor que quienes la apoyan "(...) se apresuran a expresar que es un contrato con características peculiares, sui generis, pero contrato a fin de cuentas, desde que es el acuerdo de voluntades el creador de la relación jurídica (...)". Ramos Pazos, René, Derecho de familia, Editorial Jurídica de

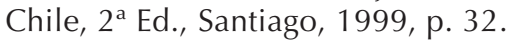

No obstante, esta postura ha sido criticada básicamente por la escasa, o prácticamente nula posibilidad de hacer primar la autonomía de la voluntad por sobre la ley, que es la que impone los derechos y deberes entre los cónyuges. En este sentido De Verda y Beamonte, José, cit. señala que "no se puede pretender aplicar al matrimonio esquemas propios del contrato, en concreto el cumplimiento forzoso en forma específica de las obligaciones; y ello porque el matrimonio no es un contrato, sino un negocio jurídico de Derecho de Familia, que afecta profundamente a la persona de los cónyuges, en la medida que les impone plena comunidad de vida, material y espiritual la cual no tiene parangón posible con ninguna de las relaciones nacidas de la celebración de un contrato".

47 Albaladejo, Manuel, Curso de derecho civil, Tomo IV, Derecho de familia, EDISOFER, 10ª Ed., Madrid, 2006, p. 32. 
siempre que haya un ligamen o vínculo jurídico cualquiera que sea su fuente ${ }^{48}$. Por otro lado, no se descartaría el poder demandar por dicha vía el daño moral sufrido, considerando además la general aceptación hoy en día de la reparación de los daños morales contractuales ${ }^{49}$.

\section{Incumplimiento del deber de fidelidad matrimonial en la Ju- risprudencia española ${ }^{50}$}

Siguiendo la tendencia tradicional, nos encontramos con dos sentencias del Tribunal Supremo español, las cuales han sido precedentes de una línea seguida por muchos años, y que tuvieron el mérito de poner en el tapete el tema en cuestión ${ }^{51}$.

48 Sancho Villarreal, Luis, obr. cit., p. 126. Vargas Aravena, David, obr. cit. p. 331.

En este sentido afirma Llamas Pомвo, Eugenio, obr. cit. que "por más que consideremos o no el matrimonio como un contrato (cada vez lo parece más), la existencia de unos deberes inherentes a esa relación jurídica encaja mucho más en el esquema de la indemnización derivada del daño inherente a la contravención del tenor de las obligaciones (art. 1101) que en el del genérico alterum non laedere; la duty situation precedente a toda responsabilidad civil está perfectamente tipificada en los deberes conyugales establecidos por la ley y consentidos por los cónyuges, y no viene dada por el mero deber de prudencia y diligencia".

En parece pronunciarse, la Corte de Apelaciones de Iquique de 26 de noviembre de 2008 (ROL 7542008) que revoca decisión de primera instancia que ordena a los demandados (ex mujer y amante de esta) pagar al demandante la suma de 20 millones de pesos a título de daño moral por el dolor y aflicción que significó para este el saber que el que siempre consideró su hijo no era tal, sino fruto de una relación extramarital de su entonces cónyuge (sin perjuicio de haber reclamado asimismo daño emergente y lucro cesante los que fueron desestimados y no fueron objeto de apelación). El actor fundamentaba legalmente su acción en la norma especial del artículo 197 del Código civil chileno, cuyo inciso segundo obliga a indemnizar los perjuicios que cause una persona que ejerce una acción de filiación de mala fe o con el propósito de dañar la honra de la persona demandada -por la tardanza en impugnar y reclamar la paternidad-y en las normas generales de la responsabilidad extracontractual de los artículos 2314 y siguientes del Código civil chileno.

Sin embargo, la Corte estimó que lo correcto, desde el punto de vista de la moralidad y de las buenas costumbres, habría sido que tales acciones se hubiesen interpuesto inmediatamente conocida la paternidad. Desde ese punto de vista, la conducta del demandado podría ser reprochable, como lo sería también el hecho mismo de la infidelidad, no considerándolo apto ni suficiente para justificar una acción indemnizatoria.

Asimismo, en el considerando décimo quinto se destaca "que en este orden de ideas, podría estimarse que el hecho dañoso consiste precisamente en la infidelidad de la cónyuge y justificar con ello la indemnización de perjuicios, sin embargo, siendo el matrimonio esencialmente un contrato, estaríamos frente a un incumplimiento contractual por el que no se ha accionado y por lo tanto no es objeto de la litis"

49 Vid. por todos Rodríguez Guitián, Alma, La reparación del daño moral en la contratación inmobiliaria / en/ Revista de Derecho. Universidad del norte, $n^{\circ} 30$, Barranquilla, 2008, pp. 141-163. Nieto Alonso, Antonia, obr. cit., pp. 1115- 1198

50 Vid. enumeración y análisis crítico de la jurisprudencia española al respecto, en López de la Cruz, Laura, obr. cit., pp. 24 y ss.; Colás Escandón, Ana, obr. cit., pp. 336-348.

51 Cabe destacar que ambas sentencias son del mismo ponente Excmo. Sr. don Alfonso Barcalá TrilloFigueroa 
Dichas sentencias giran en torno al incumplimiento del deber de fidelidad, aunque sumado al hecho de la procreación de un hijo extramatrimonial con ocultación al cónyuge, más el pago de los alimentos desembolsados hasta entonces. Ambas son bastante semejantes en cuanto a los hechos y en la resolución, pero no en la ratio decidendi ${ }^{52}$ :

Así, en primer lugar cabe mencionar la sentencia de 22 de julio de 1999 (RJ $1999 \backslash 5721)$. Dicha sentencia rechaza la indemnización solicitada por el marido a su ex esposa, al descubrir que ella le había sido infiel y que, por tanto, el vínculo biológico que creía tener con su hijo no existía. La base para rechazar dicha indemnización por daño moral, fue el no existir actuación dolosa por parte de la madre. A juicio del Tribunal Supremo, la madre no actuó de forma consciente y continuada al ocultar dicho hecho, pues con anterioridad a las pruebas de paternidad, ella no habría tenido conocimiento que el padre de su hijo no era el demandante ${ }^{53}$.

En segundo lugar, nos encontramos con la citada sentencia del Tribunal Supremo de 30 de julio de 1999, que pese a considerar el quebrantamiento de los deberes conyugales como merecedor de un innegable reproche ético-social, considera, sin embargo, que la única consecuencia jurídica que contempla la legislación sustantiva, es la de asignar al incumplimiento de tales deberes el constituirse como causa de separación matrimonial, pero no lo considera como hecho determinante de una indemnización, lo que se deduce de "la propia naturaleza del matrimonio"54.

Se ha cuestionado el criterio adoptado por dichas sentencias, pues ponen de manifiesto la incongruencia del Tribunal Supremo en estas materias. Se cita como ejemplo, una conocida sentencia de 26 de noviembre de 1985 (RJ 1985\5901) que concedió indemnización por daño moral a la mujer producto de la nulidad de su matrimonio, basado en que se había frustrado en ella la idea lucrativa de asistencia material que comporta el matrimonio, así como la esperanza de lograr una familia legítimamente constituida. Se considera, además, como hecho probado por confesión del demandado, que "fingió casarse con ella solo para disfrutarla, y con el fin de poseerla carnalmente hizo una comedia de matrimonio eclesiástico, pero con el propósito firme de abandonarla desde el momento en que se cansase físicamente de ella". Por lo tanto, se apreció como variedad, dentro de la conducta dolosa, una clara reserva mental como vicio de la declaración de voluntad al contraer matrimonio. Y

52 Razón por la que se ha estimado que dichas sentencias no sientan jurisprudencia. De Verda y Beamonte, José, obr. cit.

53 Difiere en este punto Ragel, ya que para él, en la mayoría de los supuestos, la infidelidad es un incumplimiento conyugal doloso, porque el cónyuge infiel es perfectamente consciente de que está vulnerando un deber matrimonial, uno de los más relevantes, pues está incluido en los artículos que el juez, alcalde o funcionario leen antes de preguntar a los contrayentes y declarar celebrado un matrimonio (arts. 58 y 68 CC). Ragel Sánchez, Luis, obr. cit., pp. 153-163.

54 Vid. Díez-Picazo, Luis, El escándalo del daño moral, Aranzadi, Pamplona, 2008, p. 43. 
ante esta concesión de indemnización por daño moral a la mujer "sin problemas", se critica la especial y elevada sensibilidad de la Sala de lo Civil del Tribunal Supremo hacia los sentimientos de la mujer en dicha sentencia, poniéndose hincapié en que "no existe la misma sensibilidad hacia el sentimiento de los varones" 55 en las sentencias de 1999.

En dicho caso, cabe hacerse la pregunta crítica de por qué la mujer engañada respecto de las auténticas intenciones matrimoniales de su pareja puede conseguir indemnización del daño moral, y no lo podría obtener el marido que tras años de matrimonio, descubre la continuada infidelidad de su mujer y el carácter adulterino de los hijos que creía suyos ${ }^{56}$, pues su aflicción podría ser mayor aún ${ }^{57}$.

Sin embargo, especial interés en esta materia reviste la evolución que surge a través de la jurisprudencia de las Audiencias Provinciales, que con inéditas sentencias (en adelante SAP), tales como las de Valencia de 2 de noviembre de 2004 (AC

55 Sin perjuicio que puede que esta actitud no sea deliberada "sino reflejo del aire que se respira en nuestra sociedad, de vigilancia microscópica hacia el problema de la mujer, en la que cualquier decisión desafortunada del juez tiene importantes repercusiones en los medios de comunicación...". Ragel Sánchez, Luis, obr. cit., p. 162.

Comentando la sentencia del Tribunal Supremo de 26 de noviembre 1985, Carrasco Perera es bastante crítico con dicha resolución la que califica de "memorable monumento a la hipocresía social más descarnada", pues "es evidente que no procedía ningún tipo de indemnización por ningún sedicente daño moral... y es evidente que lo que nunca debería haber ocurrido es que un tribunal español reconociese efectos civiles a una escandalosa resolución canónica que sanciona la nulidad del matrimonio por la razón de que el marido era incapaz de ver en la mujer sino un instrumento de satisfacción del gozo sexual...". Carrasco Perera, Ángel, 2006 obr. cit., p. 521.

56 Carrasco Perera, Ángel, obr. cit., p. 518.

57 Así Ragel Sánchez, estima que hubo elementos suficientes para conceder una indemnización por daño moral al demandante en la sentencia de 1999, pues "derivada de la imputabilidad del incumplimiento de la obligación contractual de fidelidad-lealtad por parte de la esposa (artículo 1101 del Código Civil). El contratante incumplidor no solo incumplió el estricto deber de fidelidad en su vertiente sexual, sino que también transgredió el más amplio deber de actuar de buena fe, como sinónimo de lealtad o recta conducta a que está obligado todo contratante ex artículo 1258. El comportamiento de la demandada fue doloso, afrentoso y agraviante: sin lugar a dudas supuso grave frustración y daño moral al demandante, al menos tan intenso como la frustración de la mujer que vio que sus expectativas de vida segura y familiar quedaban truncadas por la sentencia de nulidad matrimonial a la que hemos hecho referencia". Ragel Sánchez, Luis, cit., p. 163.

En igual sentido pero refiriéndose a la infracción del deber de fidelidad en sí, la Corte de Apelaciones de Santiago en sentencia de 10 de noviembre de 2009 (ROL 7738-07), sostiene en su considerando vigésimo que "si se tiene en consideración -que los delitos se caracterizan por el dolo y los cuasidelitos por la culpa- resulta en extremo dificultoso concebir que un adulterio se haya cometido por uno de los cónyuges con el propósito único y deliberado de causar daño al otro cónyuge, como así también, resulta difícil de imaginar un adulterio cometido simplemente por culpa o negligencia. El adulterio, como fenómeno sociológico de la humanidad, no puede encuadrarse bajo los parámetros de la responsabilidad civil extracontractual. 
$2004 \backslash 1994)^{58}$ y la SAP de 5 de septiembre de 2007 (JUR 2007\340366), han abierto la puerta a la responsabilidad civil en el terreno de los deberes conyugales. Dichas sentencias tratan también del adulterio de la demandada y de la ocultación de la filiación de o los hijos que el demandante durante algún tiempo había creído suyos. No obstante, dan cabida a la indemnización del daño moral sufrido por este, acudiendo como remedio indemnizatorio a la responsabilidad extracontractual del artículo 1902 del Código Civil.

Es así como, la primera de ellas, se basa especialmente en la conducta dolosa de los demandados, interpretando a contrario sensu la citada sentencia de 22 de julio de $1999^{59}$.

El Tribunal Ilegó a dicha conclusión, basándose principalmente en las siguientes apreciaciones de los hechos:

(i) Los demandados actuaron de forma negligente en la concepción de los hijos (puesto que desde un inicio tenían conocimiento que los métodos anticonceptivos que utilizaban no eran seguros) y de forma dolosa en su ocultación al actor.

(ii) El posterior conocimiento de la verdad por el esposo, como hecho desencadenante de un daño que debe ser resarcido

(iii) En que si bien la infidelidad no es indemnizable, sí lo es la procreación con ocultación a su cónyuge.

En este punto Ilama la atención que la Audiencia equipara el daño sufrido a la pérdida física de un hijo, considerando la sentencia que la pérdida de contacto con los tres menores que el demandante creía hijos suyos, según todos los facultativos intervinientes, "genera un sufrimiento que puede ser superior al de la muerte de los menores al no poder elaborar el duelo como respuesta a la pérdida sufrida... tras el examen de todos los informes, llegamos a la conclusión que ha existido una dolencia que ha sido muy grave, con riesgo para su vida, por sus

58 Comentada por Farnós Amorós, Esther, El precio de ocultar la infidelidad /en/ Indret, 2/2005, pp. 1-12 [on line], [última consulta: 31 de julio de 2011]. Disponible en World Wide Web: http://www.indret.com/es/

59 Critica este punto de la sentencia De Verda y Beamonte, por estimar que esta "realiza una lectura a contrario de la primera sentencia de 22 de julio de 1999 que me parece aventurada. De ella deduce que, de haberse probado que la mujer había silenciado la falsa paternidad del marido, y solamente en este caso (no, por lo tanto, si no conocía este extremo), el Tribunal Supremo, hubiese estimado la pretensión resarcitoria del marido engañado. Yo creo que intentar adivinar lo que el Supremo hubiera dicho, de haberse planteado este supuesto de hecho, es una pura conjetura y, para ser honesto, no tengo muy claro que se hubiera pronunciado a favor del resarcimiento". De Verda y Beamonte, José, obr. cit., p.18 
ideas de suicidio, y todo generado, no por la separación matrimonial, sino por la pérdida de los que consideraba sus hijos, con una entidad semejante a la pérdida física de estos..." (Considerando 10) ${ }^{60}$.

En un sentido similar se vuelve a pronunciar la Audiencia Provincial de Valencia en Sentencia de 5 de septiembre de 2007. No obstante, se rebaja la cantidad concedida en primera instancia, atendiendo a los siguientes factores: el escaso tiempo de convivencia con el menor, y su convicción casi desde su nacimiento que el hijo no era suyo ${ }^{61}$.

Así, la mayoría de las sentencias que se pronuncian al respecto, recalcan la necesidad de una actuación dolosa por parte de la demandada en cuanto a ocultar la verdadera paternidad al otro cónyuge, de no ser así, no procedería la indemnización por daño moral. En este sentido, la SAP de Barcelona de 31 de octubre de 2008 (JUR $2009 \backslash 93$ ) y de 23 de julio de 2009 (JUR 2009\464365); SAP de Segovia de 11 de diciembre de 2008 (JUR 2008\148138); SAP de León de 30 de enero de 2009 (JUR 2009\192431); SAP de Murcia de 18 de noviembre de 2009 (AC 2010\60) ${ }^{62}$.

No obstante, la Audiencia Provincial de Barcelona, en sentencia de 16 de enero de 2007 (JUR 2007\323682) ${ }^{63}$, concede la indemnización por daño moral al cónyuge actor, por la pérdida de afectos y el vacío emocional equivalente o muy próximo a la pérdida definitiva de un ser querido, al descubrir la verdad biológica de su hija, causado -a diferencia de los casos anteriores- por el incumplimiento culpable de la demandada.

En la misma línea, la SAP de Cádiz de 3 de abril de 2008 (JUR 2008\234675) concede también indemnización por daño moral por incumplimiento negligente, con

$60 \mathrm{Al}$ referirse a este aspecto de la referida sentencia Carrasco Perera advierte en esta "el lenguaje es tan refinadamente correcto, y el argumento de tan exquisito tacto, que el daño moral acaba consistiendo en que el marido "pierde" tres hijos. Resulta entonces que la fuente del daño no es la conducta infiel, ni el dolo siquiera, sino el descubrimiento de la verdad, que ha sido el desencadenante del daño. Hipócritamente, no se reprocha el adulterio, ni el engaño sino la falta de prudencia que llevó a que todo se supiera". Carrasco Perera, Ángel, obr. cit., p. 3.

61 A propósito de esta sentencia Díez-Picazo considera que queda en la penumbra cuál sería el hecho determinante del daño moral: si es la infidelidad con la consiguiente procreación de un hijo extramatrimonial, la ocultación de la verdad al cónyuge o el hecho de que este hubiera de descubrirla posteriormente, "naturalmente, hay que admitir que para el demandante puede ser depresivo, pero la cuestión es si se trata de un daño resarcible". Díez-Picazo, Luis, obr. cit.

62 Vid. Colás Escandón, Ana, cit., pp. 343-344.

63 Comentada por Farnós Amorós, Esther, Indemnización de daño moral derivado de ocultar la paternidad /en/ Indret, 4/2007, pp. 1-25 [on line], [última consulta: 31 de julio de 2011]. Disponible en World Wide Web: http://www.indret.com/es/ 
la salvedad que, además, estima que el deber de fidelidad es un deber jurídico cuya violación es susceptible de ser indemnizada vía art. 1902. Señala asimismo, que la doctrina tradicional de las STS de 22 y 30 de julio de 1999 ya no resulta aplicable, en consideración a la reforma introducida por la ley 15/2005.

Así, afirma que "en este sentido quien contrae matrimonio adquiere la legítima expectativa a que su cónyuge lleve a efecto los compromisos que adquirió al prestar su consentimiento y debe tener derecho a obtener una indemnización si el incumplimiento cualificado de aquellos le ha causado un daño. Ello debería legitimar las acciones indemnizatorias que entable cualquiera de los cónyuges por la infidelidad del otro si acredita que con ello se le ha causado un daño moral o económico apreciable, fuera del padecimiento psicológico ordinario que sigue a cualquier ruptura de pareja. $Y$ ello aunque tal posición pudiera generar una inflación de pleitos en tal sentido, que consideramos que no es argumento de peso mientras esté vigente el art. 1902 del Código Civil. La recta aplicación de cuanto se ha dicho al supuesto de autos justifica la estimación de la demanda. El incumplimiento del deber de fidelidad cualificado en el caso de autos por la ocultación de la Sra. Marta a su esposo del mantenimiento de relaciones sexuales simultáneas con otro hombre sin procurar la averiguación de quien podía resultar ser el padre tras su embarazo, con la consiguiente atribución de la paternidad al Sr. Diego, justifica la presencia de un ilícito civil susceptible de generar la responsabilidad de la demandada. Cuestión distinta será la de determinar la entidad del daño causado y su cuantificación".

En definitiva, de este apartado podemos apreciar que la jurisprudencia española mayoritariamente sigue considerando a los deberes conyugales como meros deberes éticos, de tal manera que de su infracción no se derivan más consecuencias jurídicas que las específicamente previstas para ellas, y por ende, no serían aplicables las normas de responsabilidad civil en caso de mero incumplimiento del deber de fidelidad.

No obstante, ha abandonado una rígida postura inicial, dando pie a la aplicación del art. 1902 en aquellos casos en que exista una conducta dolosa -o negligente en algunos casos- por parte del cónyuge infractor. Sin embargo, separa el incumplimiento del deber de fidelidad, de la ocultación y posterior descubrimiento de la verdadera paternidad biológica, como si fuesen hechos aparte, lo que a nuestro juicio es un error, pues es una consecuencia directa de dicha infracción.

Es de esperar que con el tiempo exista una mayor claridad al respecto, estableciendo los tribunales los criterios más objetivos posibles, a la hora de resolver una situación en que se han originado daños fruto de incumplimiento de un deber conyugal. 


\section{Conclusiones}

De lo expuesto, tanto de los argumentos para denegar la aplicación de las normas de responsabilidad civil -ya sea contractual o extracontractual-, como del examen de algunos ejemplos jurisprudenciales sobre esta materia, es posible afirmar que, si bien no es fácil establecer una regla general de aplicabilidad que resulte adecuado y conduzca a soluciones justas, no cabe descartar dicha posibilidad a priori, pues el Derecho de Familia no forma un campo de inmunidad en el Ordenamiento jurídico.

En definitiva, somos de la opinión que los deberes conyugales, y en particular el deber de fidelidad, constituyen una obligación legal jurídicamente exigible, pues son integrantes del núcleo mismo de la causa matrimonial, y si bien no revisten un carácter esencialmente patrimonial, sino más bien un marcado carácter ético, puede su incumplimiento, atendiendo las circunstancias, derivar en una pretensión indemnizatoria por parte del cónyuge afectado.

De este modo, creemos que descartar dicha pretensión, basándonos en el principio de especialidad en el Derecho de Familia, ofrece una protección limitada al cónyuge que sufre una violación al derecho de fidelidad y a la generalidad de los deberes conyugales. En efecto, somos partidarios del resarcimiento de los daños que derivan de una conducta infiel por parte de alguno de los cónyuges, tales como los extrapatrimoniales o morales sufridos por la humillación, deterioro de la familia, el honor, la "pérdida de hijos" que se creían propios, aunque, claro está, atendiendo a diversos factores, tales como la gravedad, reiteración y las consecuencias derivadas de la infidelidad, por lo que siempre deberá tenerse en cuenta el caso concreto.

Sin embargo, por lo nuevo de esta problemática, aún subsisten dudas respecto de cual sería la vía adecuada para reclamar los daños derivados de una conducta infiel -contractual o extracontractual-. Aunque estimamos que por su calidad de deberes jurídicos derivados del matrimonio, podríamos enmarcar dicha responsabilidad en el ámbito contractual, la discusión sigue abierta y admite argumentos en ambos sentidos, por lo que a través de este trabajo solo pretendemos dejar abierto el debate en dicho aspecto. 


\section{Bibliografía}

Albaladejo, Manuel, Curso de derecho civil, Tomo IV, Derecho de familia, $10^{\mathrm{a}}$ Ed., EDISOFER, Madrid, 2006.

Barros Bourie, Enrique, Tratado de responsabilidad extracontractual, Ed. Jurídica de Chile, Santiago, 2006.

Carrasco Perera, Ángel, Derecho de familia. Casos, reglas, argumentos, Dilex, Madrid, 2006.

Carrasco Perera, Ángel, El precio de la infidelidad /en/ Actualidad Jurídica Aranzadi, $\mathrm{n}^{\circ}$ 666, abril 2005.

Colás Escandón, Ana, Nuevos daños indemnizables: las relaciones de familia /en/ HeRRAdor Guardia, Mariano (coord.) Derecho de Daños, Sepin, Madrid, 2011.

De Verda y BeAmOnte, José, Responsabilidad civil y divorcio en el derecho español: resarcimiento del daño moral derivado del incumplimiento de deberes conyugales /en/ Diario La Ley, n 6676, 21 de marzo de 2007, [on line], [última consulta: 31 de julio de 2011]. Disponible en World Wide Web: http://www.laley.es

Díez-PıcAzo, Luis, El escándalo del daño moral, Aranzadi, Pamplona, 2008.

Díez-Picazo, Luis, Gullón Antonio, Sistema de derecho civil. Derecho de familia. De-

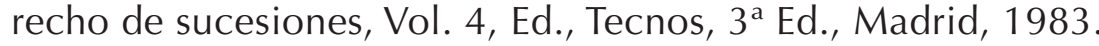

Domínguez Muelmo, Andrés, La supresión de las causas de separación y divorcio en la ley 15/2005 y sus repercusiones en el Derecho Civil /en/ Revista jurídica de Castilla y León, $n^{\circ} 13$, agosto 2007.

FARNÓs Amorós, Esther, El precio de ocultar la infidelidad /en/Indret, 2/2005, pp. 1-12 [on line], [última consulta: 31 de julio de 2011]. Disponible en World Wide Web: http://www.indret.com/es/

FARNós AmOrós, Esther, Indemnización de daño moral derivado de ocultar la paternidad /en/ Indret, 4/2007, pp. 1-25, [on line], [última consulta: 31 de julio de 2011]. Disponible en World Wide Web: http://www.indret.com/es/

Ferrer Riba, Josep, Relaciones familiares y límites del derecho de daños /en/ CabanilLas SÁnCHEZ, Antonio, et al. (coord.), Estudios jurídicos en homenaje al profesor Luis Díez-Picazo, T. II, Civitas, Madrid, 2003. 
Fleitas Ortiz de Rozas, Abel, Responsabilidad por daños y perjuicios entre cónyuges, [on line], [última consulta: 15 de marzo 2010]. Disponible en World Wide Web: http://www.rubinzal.com.ar/revistas/danos/danoenlarelacion_defamilia(danos)-e. $\mathrm{htm} \# 2$

Lacruz Berdejo, José, Sancho Rebullida, Francisco, Elementos de Derecho Civil IV. Derecho de Familia, Bosch, Barcelona, 1982.

Llamas Pombo, Eugenio, Divorcio y responsabilidad civil /en/ Práctica de derecho de Daños: Revista de responsabilidad civil y seguros, n 49, mayo 2007.

LÓPEZ DE LA CRUZ, Laura, El resarcimiento del daño moral ocasionado por el incumplimiento de los deberes conyugales /en/ Indret, 4/2010, pp. 1-40 [on line], [última consulta: 31 de julio de 2011]. Disponible en World Wide Web: http://www. indret.com/es/.

Marín García de Leonardo, Teresa, Remedios indemnizatorios en el ámbito de las relaciones conyugales /en/ De Verda y Beamonte, José (Coord.), Daños en el derecho de familia, Aranzadi, 2006.

Medina, Graciela, Daños derivados del divorcio [on line], [última consulta: 31 de julio de 2011]. Disponible en World Wide Web:

http://www.gracielamedina.com/assets/Uploads/articulo/pdf/09-11-06A-1.pdf.

Nieto Alonso, Antonia, Daños morales derivados del incumplimiento o defectuoso cumplimiento de una obligación contractual (a propósito de alguna jurisprudencia reciente) /en/ Anuario de Derecho Civil, Vol. 59, n 3, 2006.

Novales Alquézar, María, Hacia una teoría general de la responsabilidad civil en el derecho de familia. El ámbito de las relaciones personales entre cónyuges /en/ Revista jurídica del notariado, ${ }^{\circ}$ 60, octubre-noviembre 2006.

PAtTı, Salvatore, Famiglia e responsabilità civile, Giuffrè, Milán, 1984.

Pérez MAYOR, Adrián, Crisis matrimoniales e indemnización por daño moral /en/ Revista jurídica de Catalunya, nº 1, año CIII, 2004.

Ragel SÁnCHeZ, Luis, Denegación de indemnización del daño moral causado por infidelidad matrimonial. Comentario a STS de 30 de julio de 1999 /en/ Cuadernos Civitas de jurisprudencia civil, nº 52, enero-marzo 2000.

Ramos Pazos, René, Derecho de familia, Ed. Jurídica de Chile, 2ª Ed., Santiago, 1999. 
Roca I Trías, Encarna, La responsabilidad civil en el derecho de familia. Venturas y desventuras de cónyuges, padres e hijos en el mundo de la responsabilidad civil /en/ Moreno Martínez, Juan (Coord.), Perfiles de la responsabilidad civil en el nuevo milenio, Dykinson, Madrid, 2000.

Rodríguez Guitián, Alma, La reparación del daño moral en la contratación inmobiliaria /en/ Revista de Derecho. Universidad del norte, $\mathrm{n}^{\circ}$ 30, Barranquilla, 2008.

Rodríguez Guitı́́n, Alma, Responsabilidad civil en el derecho de familia: Especial referencia al ámbito de las relaciones paterno-filiales, Aranzadi, Pamplona, 2009.

Sancho Villarreal, Luis, El deber de fidelidad conyugal como obligación jurídica y consecuencias de su infracción. Comentario a la STS de 30 de julio de 1999 / en/ Revista de derecho de familia, abril 2001.

Vargas Aravena, David, Daños civiles en el matrimonio, La Ley, Madrid, 2009.

Vázquez Iruzubieta, Carlos, Comentario al artículo 68 del Código Civil /en/ Matrimonio, separación y divorcio. Comentarios a los artículos 42 a 107 del Código Civil, Vlex, 2009, [on line], [última consulta: 31 de julio de 2011]. Disponible en World Wide Web: http://vlex.com/source/matrimonio-nulidad-separacion-divorcio-comentario-codigo-civil-608\#ixzz0kuxhlEpL 